\title{
Physical Properties of Sputtered Indium-doped ZnO Films Deposited on Flexible Transparent Substrates
}

\author{
Hector Eduardo Silva-Lopez ${ }^{a *}$, Becerril Silva Marcelino ${ }^{a}$, Angel Guillen-Cervantes ${ }^{a}$, \\ Orlando Zelaya-Angel ${ }^{a}$, Rafael Ramirez-Bon ${ }^{b}$ \\ ${ }^{a}$ Departamento de Física, Centro de Investigación y de Estudios Avanzados, Instituto Politecnico \\ Nacional (IPN), Apartado Postal 14-740, D.F. 07300, México \\ ${ }^{b}$ Centro de Investigación y de Estudios Avanzados, Instituto Politecnico Nacional (IPN), Unidad \\ Querétaro, Apartado Postal 1-798, Querétaro, Qro. 76001, México
}

Received: March 24, 2018; Revised: July 07, 2018; Accepted: August 16, 2018

\begin{abstract}
Indium-doped zinc oxide (IZO) polycrystalline thin films were grown on polyethylene terephthalate (PET), polyethylene naphthalate (PEN), and as reference on 7059 Corning glass substrates at room temperature by radio frequency magnetron sputtering from a target prepared with a mixture of $\mathrm{ZnO}$ and $\mathrm{In}_{2} \mathrm{O}_{3}$ powders. The structural, optical, and electrical properties of the films were analyzed and compared. The IZO polycrystalline films showed $n$-type conductivity. The electrical resistivity drops significantly, and the carrier concentration increases as a consequence of In incorporation within the $\mathrm{ZnO}$ crystalline lattice. In both cases the changes are of several orders of magnitude. The resistivity obtained was $3.1 \pm 0.5 \times 10^{-3} \Omega$-cm for an IZO sample grown on PET with a carrier concentration of $3.1 \pm 0.7 \times 10^{20} \mathrm{~cm}^{-3}$, the best mobility obtained was $27.7 \pm 0.8 \mathrm{~cm}^{2} \mathrm{~V}^{-1} \mathrm{~s}^{-1}$ for an IZO sample grown on PEN. From the results, we conclude that $n$-type IZO polycrystalline films with high transmittance, high mobility and low resistivity were obtained on flexible transparent substrates.
\end{abstract}

Keywords: Flexible transparent substrates, PET, PEN, Indium-doped zinc oxide, polycrystalline thin films.

\section{Introduction}

Transparent conducting oxide (TCO) materials such as indium tin oxide (ITO) have been of interest due to their high electrical conductivity and optical transparency. However, due to the scarcity of In reserves ${ }^{1}$, candidates for ITO replacements are necessary especially when In concentration is as high as $90 \%$ in commercial ITO glasses. $\mathrm{ZnO}$-based transparent electrodes have been extensively investigated as potential substitutes ${ }^{2,3}$. Conductive $\mathrm{ZnO}$ films have aroused increasing interest due to their applications in solar cells, gas sensors, varistors and light emitting diodes ${ }^{4-6}$. However, the electrical conductivity of $\mathrm{ZnO}$ is low compared to most $\mathrm{TCO}$ electrodes. To increase $\mathrm{ZnO}$ conductivity, group III elements ( $\mathrm{Al}, \mathrm{Ga}$, and $\mathrm{In}$ ) have been used as substitutional dopants for $\mathrm{Zn}$, with Al-doped $\mathrm{ZnO}$ (AZO) as one of the most extensively TCO studied materials ${ }^{7,8}$. In this regard, Indium is an attractive dopant for n-type $\mathrm{ZnO}$ because has less reactivity and greater oxidation-resistance relative to Al. Therefore, Indium-doped zinc oxide (IZO) films are a promising alternative for ITO films. Nevertheless, the literature about IZO films ${ }^{9-11}$ is not as abundant as in the case of AZO films. ${ }^{2-4}$. On the other hand, in energy conversion technology the deposition on flexible substrates will be a reliable solution ${ }^{12}$. Some advantages of these substrates are: cost, they are cheaper than glass, flexibility and lighter

*e-mail: hsl@fis.cinvestav.mx weight ${ }^{13,14}$, besides plastic substrates are compatible with low temperature manufacturing processes; for instance, the thin film transistor manufacture, for the development of flexible large-area electronics ${ }^{15,16}$, where TCOs deposited at low temperature and with high mobility are required ${ }^{17}$. Plastic materials which have been used for substrate purposes are: acrylic, polyethylene terephthalate (PET), polyethylene naphthalate (PEN), polycarbonate, etc., ${ }^{12-15,17-19}$. Due to their good optical and mechanical properties and easy processability, PEN and PET materials stand out as substrates for applications in flexible electronics. For this work, we deposited IZO thin films on PEN, PET, and as reference on alkali-free borosilicate glass substrates by radio frequency (rf) magnetron sputtering. We investigated the structural, optical, and electrical properties of the sputtered thin films grown at room temperature (RT). The electrical resistivity of IZO thin films decreases by four orders of magnitude; meanwhile its carrier concentration increases three to four orders of magnitude as compared with an undoped $\mathrm{ZnO}$ reference film. Furthermore, the IZO film deposited on a PEN substrate has excellent transmittance in the visible range and very high mobility figures.

\section{Experimental Details}

Indium-doped zinc oxide (IZO) films were deposited onto, PET, PEN, and as reference a $\mathrm{ZnO}$ film and an IZO 
film were grown on 7059 alkali-free borosilicate (Corning Glass) substrates at RT in a rf magnetron sputtering system equipped with a water-cooled cathode. The experimental conditions for the growth provide $\mathrm{ZnO}$ samples with high structural and electrical properties as reported previously ${ }^{8}$. The rf power employed was $20 \mathrm{~W}$ and the distance between the target and substrate $3.5 \mathrm{~cm}$. The chamber was evacuated to a pressure of $1.33 \mathrm{mPa}$ before the addition of pure Ar gas. The total Ar pressure was kept at $1.33 \times 10^{-1} \mathrm{~Pa}$ during the deposition process. The films were deposited for $45 \mathrm{~min}$. The IZO target, which has an area of $4.92 \mathrm{~cm}^{2}$ and a weight of 5.2 grams was prepared from 4 grams of $\mathrm{ZnO}$ (purity, 99.99\% from Sigma-Aldrich) and 1.2 grams of $\operatorname{In}_{2} \mathrm{O}_{3}$ (Sigma-Aldrich, purity $99.99 \%$ ) powders. Oxide powders were mixed and compressed with 15 Tons for 8 hours to form a 2 inches diameter target. The $\mathrm{ZnO}$ target used for the growth of the $\mathrm{ZnO}$ reference film, was composed only with 5.2 grams of zinc oxide powder, target was compressed at 15 Tons for 8 hours. The $\mathrm{ZnO}$ and IZO reference films deposited on glass were labeled as $\mathrm{ZnO}$ and $\mathrm{IZO}_{1}$ respectively. IZO films grown on PET and PEN were labeled $\mathrm{IZO}_{2}$ and $\mathrm{IZO}_{3}$ respectively (see Table 1). The growths were performed under identical experimental conditions to evaluate the structural, optical, and electrical properties of IZO films deposited on plastic substrates. The crystalline structure of the films was determined by X-ray diffraction (XRD) using a SIEMENS D-5000 equipment, with the $\mathrm{Cu}-\mathrm{K} \alpha$ line (1.5406 $\AA)$. The film thicknesses were estimated by a KLA Tencor P15 profiler. The optical transmittance spectra of the films were measured in an UNICAM 8700 spectrophotometer in the $200-1000 \mathrm{~nm}$ range. IZO thin films and plastic substrates roughness measurements were obtained with an Atomic Force Microscopy (AFM) equipment model Autoprobe CP from Veeco Metrology Group. Atomic concentration measurements of the samples were evaluated by Energy Dispersive Spectroscopy (EDS) with an X-Flash 5010 detector from Bruker installed in a Jeol Scanning Electron Microscope model JSM-3600. To determine the elemental atomic concentration of $\mathrm{O}, \mathrm{Zn}$, and $\mathrm{In}$ in the films, a set of $\mathrm{ZnO}$ and IZO samples were deposited on silicon substrates to avoid oxygen contribution from the PET, PEN, and glass in the EDS measurements. The silicon substrates were placed aside of the PET, PEN, and glass substrates in each growth. The resistivity, carrier concentration, mobility and type of conductivity of the films were measured at RT using the Van der Pauw method in a Hall effect equipment. To perform electrical measurements, high purity Silver Paint (Alfa Aesar $>99 \%$ ) electrodes were deposited on the films.

\section{Experimental Results and Discussion}

Fig. 1 exhibits a diffractogram of an IZO representative sample. The XRD pattern indicates the films are polycrystalline with hexagonal wurtzite structure ${ }^{20}$. A preferred orientation along the (002) direction is observed. The right inset in Fig. 1 shows, both, the (002) interplanar distance (ID) of the samples estimated from the XRD patterns and the Bragg angle as a function of the deposited sample. $\mathrm{ZnO}_{\mathrm{b}}$ corresponds to the bulk standard data taken from literature ${ }^{21}$, and the $\mathrm{ZnO}$ sample is the undoped reference film grown on a glass substrate. Based on the $\mathrm{ZnO}_{\mathrm{b}}$ standard position in the graph, note that the (002) reflection corresponding to the studied samples shifts to lower 2( angles while the ID values increase. Similar tendency is observed for the (102) and (103) XRD reflections showed in the left inset in Fig. 1, the $2 \theta$ values of the (102) and the (103) diffraction peaks decrease in the samples. This behavior suggests expansion in the $\mathrm{ZnO}$ lattice. In the case of the $\mathrm{ZnO}$ reference sample a larger ID value compared

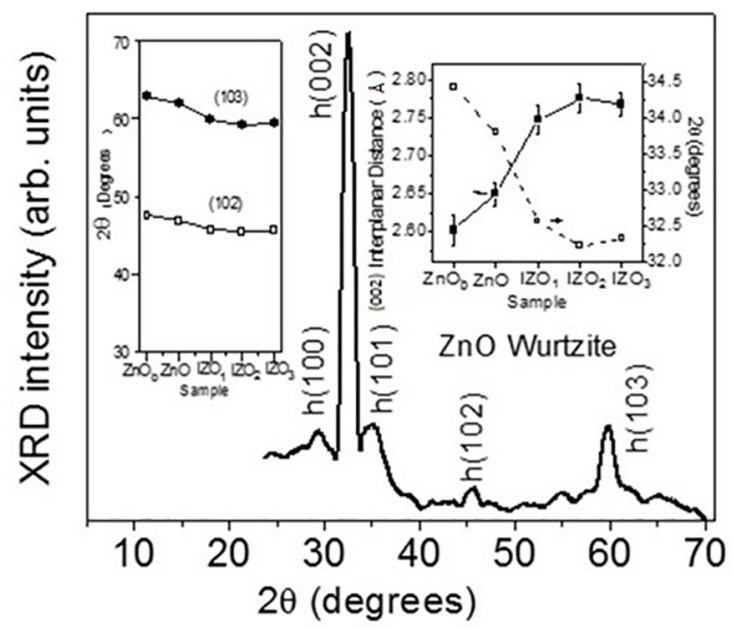

Figure 1. XRD diffractogram of an IZO representative film. The film crystallized in the hexagonal wurtzite phase with preferential orientation in the (002) direction. The insets show shifts in the interplanar distance and diffraction peak position as a function of the IZO films.

Table 1. Thickness, Grain size, roughness and band gap experimental data of the $\mathrm{ZnO}$ and IZO films grown on glass, PET and PEN by rf magnetron sputtering at RT.

\begin{tabular}{lccccc}
\hline Sample & Substrate & Thickness $(\mathrm{nm})$ & $\begin{array}{c}\text { Grain Size }(\mathrm{GS}) \\
(\mathrm{nm})\end{array}$ & $\begin{array}{c}\text { rmsroughness } \\
(\AA)\end{array}$ & $\boldsymbol{E g}(\mathrm{eV})$ \\
\hline $\mathrm{ZnO}$ & glass & $134 \pm 10$ & $16.4 \pm 1.2$ & 8.20 & $3.2 \pm 0.3$ \\
$\mathrm{IZO} 1$ & glass & $130 \pm 8$ & $13.2 \pm 0.9$ & 108 & $3.2 \pm 0.3$ \\
$\mathrm{IZO} 2$ & PET & $131 \pm 5$ & $13.0 \pm 0.5$ & 49.1 & $3.1 \pm 0.2$ \\
$\mathrm{IZO} 3$ & PEN & $128 \pm 11$ & $16.0 \pm 0.7$ & 49.6 & $3.2 \pm 0.1$ \\
\hline
\end{tabular}


with the $\mathrm{ZnO}_{\mathrm{b}}$ standard is related with the difference in the linear expansion coefficient between the film and substrate (corning glass). The linear expansion coefficient for bulk zinc oxide ${ }^{21}$ is about two orders of magnitude larger than that corresponding to the glass substrate. In despite the growth is performed at RT, due to plasma and the rf power in the magnetron sputtering system the temperature increases about $5{ }^{\circ} \mathrm{C}$. Therefore, after growth, when the film and the substrate thermalize the $\mathrm{ZnO}$ film lattice remains expanded. For the IZO samples the difference in ID values can be explained in terms of the difference in the atomic radii between $\mathrm{Zn}$ and In atoms. The In atomic radii $(81 \mathrm{pm})$ is larger than the $\mathrm{Zn}$ one ( $74 \mathrm{pm})$. Thus, the substitution of $\mathrm{Zn}$ atoms by In atoms in the films increases the lattice parameters.

From the full width at half maximum (FWHM) of the (002) XRD diffraction peak, the grain size (GS) of the films was estimated using the Debye-Scherrer formula: $G S=\varepsilon \lambda$ / $\beta \cos \theta$, where $G S$ refers to grain size, $\varepsilon$ is a constant with a value of $0.94, \lambda$ is the $\mathrm{Cu}-\mathrm{K} \alpha$ wavelength of the XRD source, $\beta$ is the FWHM of the diffraction peak measured in radians, and $\theta$ is the Bragg angle ${ }^{8}$. The films have grain size between 13 and $16.4 \mathrm{~nm}$. It was previously reported that small grain size could be due to the fact that samples were grown at
RT without a post-growth thermal annealing ${ }^{9}$. $G S$ values and thickness of the IZO films are displayed in Table 1. A detailed analysis of the surface morphology of the samples was made by AFM. $2 \mu \mathrm{m} \times 2 \mu \mathrm{m}$ images of $\mathrm{ZnO}$ and IZO samples prepared at RT are depicted in Fig. 2. There is an evident change of roughness in the $\mathrm{IZO}_{1}, \mathrm{IZO}_{2}$, and $\mathrm{IZO}_{3}$ samples compared to $\mathrm{ZnO}$. The $\mathrm{ZnO}$ sample presents root mean square (rms) roughness of $8.20 \AA$ while the samples $\mathrm{IZO}_{1}, \mathrm{IZO}_{2}$, and $\mathrm{IZO}_{3}$ have rms values of $108,49.1$, and $49.6 \AA$, respectively (see Table 1 ). This higher value in roughness for IZO samples could be probably due to the incorporation of indium in the films. Figure 3 compares the optical transmittance of the films and the PEN, PET and glass substrates. The average transmittance in the 400-1000 nm wavelength range of the undoped $\mathrm{ZnO}$ film was $78 \%$ while for the $\mathrm{IZO}_{1}, \mathrm{IZO}_{2}$, and $\mathrm{IZO}_{3}$ films average transmittance values were $79 \%, 80 \%$, and $82 \%$, respectively. It is worth to mention that sample with the highest transmittance is the sample with the largest $G S$. It is well known that samples with reduced $G S$ have poor transparency due to light scattering from grain frontiers ${ }^{7}$. The ripples observed in the transmission signal for the $\mathrm{IZO}_{2}$ sample are effect of the structure of the PET substrate, as corroborated from the PET transmission

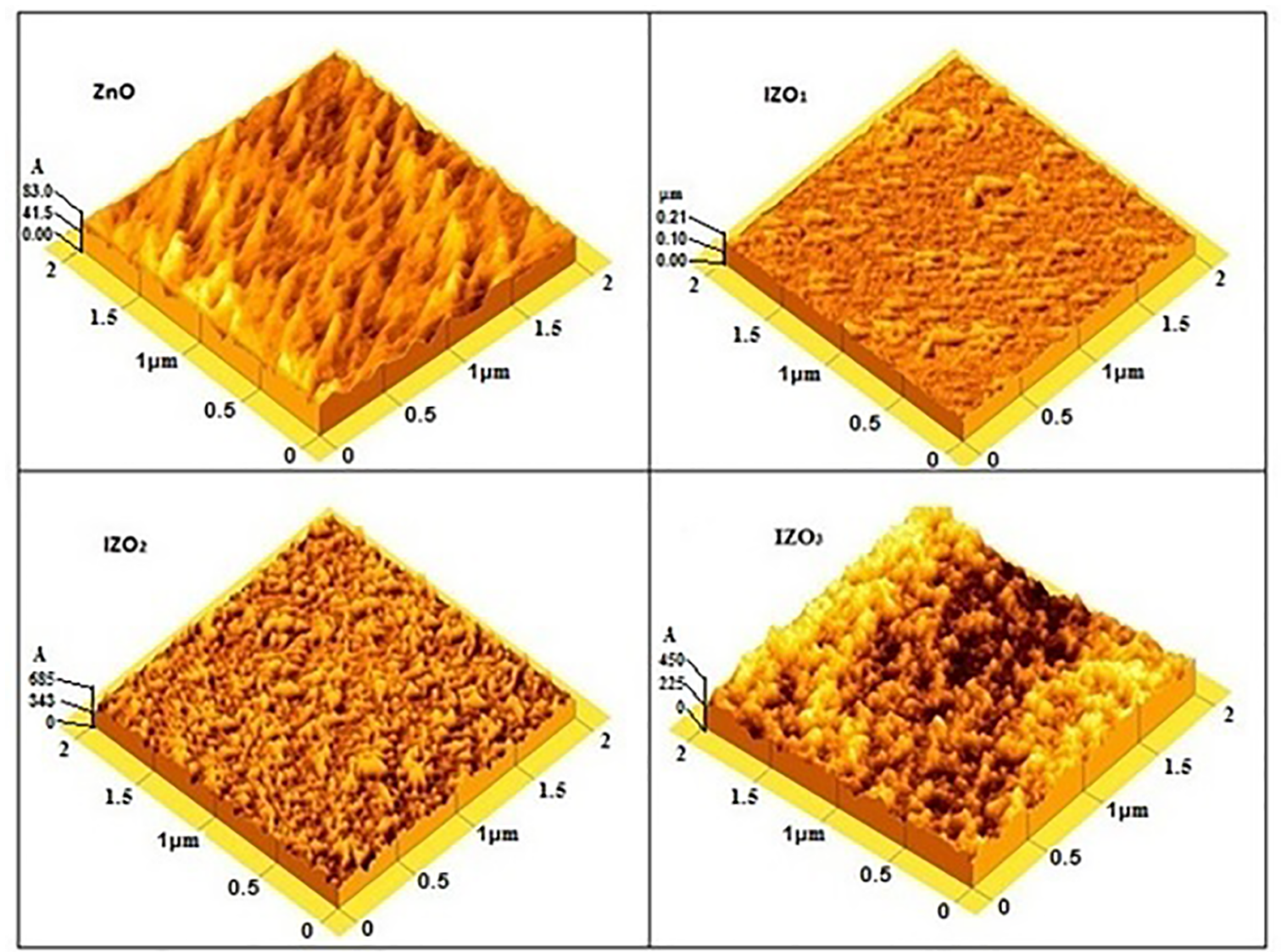

Figure 2. AFM images of $\mathrm{ZnO}$ and IZO films deposited on different substrates at RT by rf magnetron sputtering. 


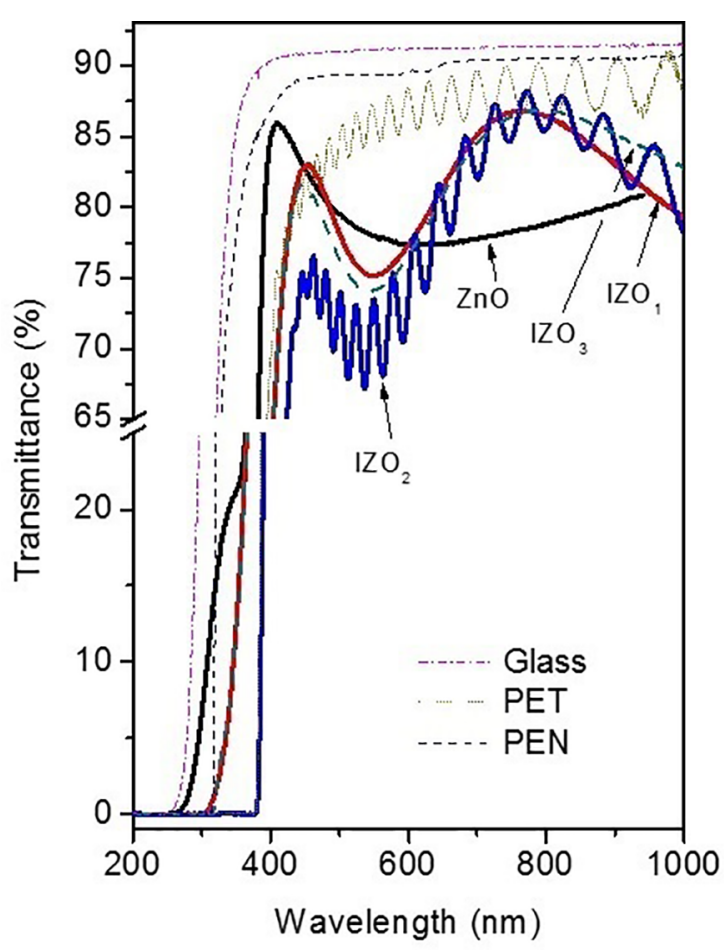

Figure 3. The optical transmittance of the $\mathrm{ZnO}$, IZO films and the PEN, PET and glass substrates.

spectrum shown in Fig. 3. The direct optical band gap $E_{g}$ was calculated using Cody's relationship ${ }^{22}: \alpha^{2}=A(h v-$ $E g$ ) where $\alpha$ is the optical absorption coefficient, $h v$ is the photon energy, $A$ is a constant, and $E_{g}$ the band gap energy. Absorption coefficients of the films for different wavelength have been calculated from the transmittance and reflection data. Table 1 summarizes the energy band gap $E_{g}$ of the films studied in this work. The data were measured several times at different points on the surface of the samples and the standard deviation values were calculated as reported. Despite the expansion of the lattice, $E_{g}$ conserves the zinc oxide value in bulk. The analysis of the chemical composition measured by EDS (Table 2) indicates that indium atoms were incorporated into the $\mathrm{ZnO}$ films at 4.5 at. $\%$ for $\mathrm{IZO}_{1}$ sample, 5.2 at. $\%$ in $\mathrm{IZO}_{2}$ and 4.1 at. $\%$ for $\mathrm{IZO}_{3}$ sample, the In incorporation in the $\mathrm{ZnO}$ lattice was of the same order in despite of the type of substrate. Fig. 4 and Table 2 show the behavior of the resistivity, carrier concentration, and mobility of the IZO samples studied in this work as a function of the substrate and GS. Note the incorporation of indium into the IZO films has a strong effect in the electrical measurements. The undoped $\mathrm{ZnO}$ film has a resistivity of 74 $\pm 2 \Omega$-cm (not shown in the graph but in the Table 2) while samples $\mathrm{IZO}_{1}, \mathrm{IZO}_{2}$, and $\mathrm{IZO}_{3}$ have resistivity of $1.8 \times 10^{-3}$, $3.1 \times 10^{-3}$, and $2.9 \times 10^{-3} \Omega$-cm, respectively. After indium doping process, every $\operatorname{In}^{3+}$ contributes with an extra electron to the number of charge carries ${ }^{7}$ although, resistivity of the IZO samples decreases compared with the undoped $\mathrm{ZnO}$

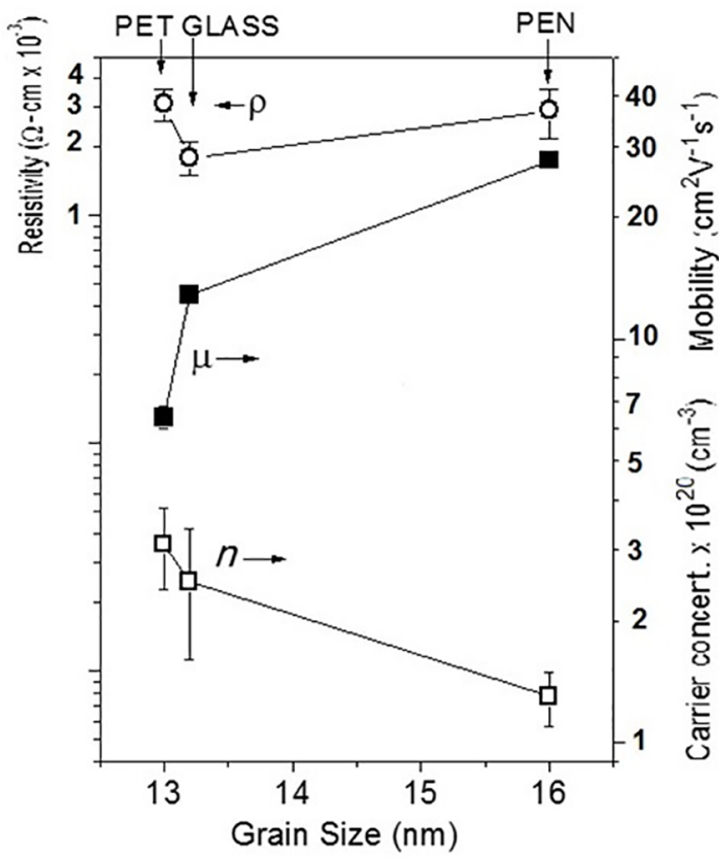

Figure 4. Resistivity ( $\rho$ ), Mobility ( () and Carrier concentration $(n)$ behavior as a function of the grain size $(G S)$ for the IZO samples. From the graph and results in Table 2 note electrical parameters change considerably compared with those measured in the reference $\mathrm{ZnO}$ sample. The inset shows the $\mathrm{ZnO}$ unit cell.

film. The resistivity for $\mathrm{IZO}_{1}, \mathrm{IZO}_{2}$, and $\mathrm{IZO}_{3}$ films drops four orders of magnitude, compared with that of the $\mathrm{ZnO}$ reference film deposited on glass. On the other hand, the carrier concentration, according to the graph in Fig. 4 and results in Table 2, varies from $9.5 \times 10^{16} \mathrm{~cm}^{-3}$ in $\mathrm{ZnO}$ to 3.1 $\times 10^{20} \mathrm{~cm}^{-3}$ in $\mathrm{IZO}_{2}$ film grown on the PET substrate. The $\mathrm{ZnO}$ and IZO films are $n$-type. The Hall mobility $\mu$ increases after In doping and shows a maximum value of $27.7 \mathrm{~cm}^{2} \mathrm{~V}^{-1}$ $\mathrm{s}^{-1}$ in sample $\mathrm{IZO}_{3}$ which was deposited on PEN. This higher Hall mobility was measured in the sample with a lower carrier concentration. Mobility trend can be explained as follows: low doping levels decrease the carrier concentration in the IZO films with a consequent reduction in electron scattering effects ${ }^{3}$, thus the Hall mobility increases. Fig. 4 also indicates that if the $G S$ decreases, (decreases while $n$ increases, which means that higher doping levels decrease the grain size in the samples for the experimental conditions reported in this work. It has been observed that the planarity of surface strongly influences the physical properties of deposited materia ${ }^{23,24}$. Although, the rms roughness of the surface of substrates was determined by AFM: glass $0.36 \pm$ $0.04 \mathrm{~nm}$, PET $2.3 \pm 0.6 \mathrm{~nm}$, and PEN $2.5 \pm 0.4 \mathrm{~nm}$. In our experiments, the $G S$ of IZO samples decreases when rms roughness of the substrate also decreases affecting $\mu$ figures, which, according with the above discussion, corroborates the influence substrate surface has on physical properties 
of deposited films. Doping efficiency for the IZO samples was calculated considering the inset in Fig. 4, the unit cell parameters were taken from reference ${ }^{21}$. The $\mathrm{ZnO}$ unit cell volume $(\mathrm{V})$ calculated was $\mathrm{V}=4.76 \times 10^{-23} \mathrm{~cm}^{3}$, taking into consideration 4 atoms per unit cell ( 2 oxygen atoms and 2 of zinc), the number of $\mathrm{Zn}$ atoms per $\mathrm{cm}^{3}$ (\#/V) is $4.2 \times 10^{22}$ at. $\mathrm{cm}^{-3}$. For $n$ - type doping, indium occupies zinc sites. The percentage of Indium in the $\mathrm{IZO}_{1}$ sample is 4.5 at.\%. By assuming that all the In atoms enter substitutionally in the $\mathrm{ZnO}$ lattice, that is, the number of In atoms in interstitials positions and in antisites is neglected. Then, the number of atoms that the In should occupy for a 100\% doping efficiency is, (an electron per each In atom), $\sim 0.045 \times 4.2 \times 10^{22} \mathrm{~cm}^{-3}$ $=0.189 \times 10^{22} \mathrm{~cm}^{-3}=1.89 \times 10^{21} \mathrm{~cm}^{-3}$. Assuming also that all the donors are ionized at room temperature, this number would be the expected majority carrier density. However, only $2.5 \times 10^{20} \mathrm{~cm}^{-3}$ active carriers were measured in the Hall experiments. Thus, the doping efficiency calculated for $\mathrm{IZO}_{1}$ is $2.5 \times 10^{20} / 1.89 \times 10^{21}=0.132=13.2 \%$. For $\mathrm{IZO}_{2}$ the efficiency results $14.2 \%$, and for $\mathrm{IZO}_{3} 7.6 \%$. Note doping efficiency is better for PET substrates an important factor considering the impact plastic substrates have in the semiconductor industry, doping efficiency values are listed in Table 2. It is worth to mention that the low resistivity figures reported in this work were measured in samples grown at RT by rf magnetron sputtering on flexible substrates and are comparable to those grown with different conditions on conducting substrates and/or in post-growth annealed samples (see Table 3) ) $^{25-31}$.

\section{Conclusion}

In summary, the structural, optical, and electrical properties of IZO films deposited under identical growth conditions at RT by rf magnetron sputtering on glass, PET and PEN substrates were investigated. IZO samples showed hexagonal phase, with (002) preferential crystalline orientation. The optical transmission was around $80 \%$ in the $400-1000 \mathrm{~nm}$ wavelength range. The lowest resistivity measured was $1.8 \pm$ $0.3 \times 10^{-3} \Omega$-cm in the sample grown on glass substrate. The carrier concentration was $3.1 \pm 0.7 \times 10^{20} \mathrm{~cm}^{-3}$ obtained in the sample grown on PET substrate. A very high Hall mobility of $27.7 \mathrm{~cm}^{2} \mathrm{~V}^{-1} \mathrm{~s}^{-1}$ was observed in the IZO film deposited on a PEN substrate. Our results showed IZO samples grown on flexible substrates are suitable for flexible TCO electrodes and applications in flexible optoelectronic devices.

\section{Acknowledgements}

The authors are grateful to M. Guerrero and R. Fragoso for their helpful technical assistance. This work was financially supported by CONACyT, México.

Table 2. Elemental atomic composition and electrical parameters of $\mathrm{ZnO}$ and $\mathrm{IZO}$ samples studied in this work.

\begin{tabular}{lccccccc}
\hline Sample & Zn(at\%) & $\mathrm{O}(\mathrm{at} \%)$ & $\mathrm{In}(\mathrm{at} \%)$ & $\begin{array}{c}\text { Resistivity }(\boldsymbol{\rho}) \\
(\Omega-\mathrm{cm})\end{array}$ & $\begin{array}{c}\text { Carrier } \\
\text { Concentration }(\boldsymbol{n}) \\
(\mathrm{cm}-3)\end{array}$ & $\begin{array}{c}\text { HallMobility }(\boldsymbol{\mu}) \\
(\mathrm{cm} 2 \mathrm{~V}-1 \mathrm{~s}-1)\end{array}$ & $\begin{array}{c}\text { Doping } \\
\text { efficiency }(\%)\end{array}$ \\
\hline $\mathrm{ZnO}$ & $48.2 \pm 2.0$ & $51.8 \pm 3.2$ & -- & $74 \pm 2$ & $9.5 \pm 0.8 \times 1016$ & $4.3 \pm 0.6$ & 13.2 \\
$\mathrm{IZO}_{1}$ & $23.3 \pm 1.5$ & $72.3 \pm 3.0$ & $4.5 \pm 0.5$ & $\begin{array}{c}1.8 \pm 0.3 \\
\mathrm{x} 10-3\end{array}$ & $2.5 \pm 0.9 \times 1020$ & $12.9 \pm 0.4$ & 14.2 \\
$\mathrm{IZO}_{2}$ & $22.4 \pm 2.7$ & $72.4 \pm 4.1$ & $5.2 \pm 0.7$ & $\begin{array}{c}3.1 \pm 0.5 \\
\mathrm{x} 10-3\end{array}$ & $3.1 \pm 0.7 \times 1020$ & $6.4 \pm 0.4$ & \\
$\mathrm{IZO}_{3}$ & $22.6 \pm 3.1$ & $73.4 \pm 4.1$ & $4.1 \pm 0.4$ & $\begin{array}{c}2.9 \pm 0.7 \\
\mathrm{x} 10-3\end{array}$ & $1.3 \pm 0.2 \times 1020$ & $27.7 \pm 0.8$ & 7.6 \\
\hline
\end{tabular}

Table 3. Comparison between data of IZO samples from scientific literature, prepared with different conditions and substrates and the results reported in this work.

\begin{tabular}{|c|c|c|c|c|c|}
\hline Technique & Resistivity $(\Omega \mathrm{cm})$ & $\begin{array}{c}\text { Transparency }(\%, \\
550 \mathrm{~nm})\end{array}$ & Substrate & $\begin{array}{c}\text { Growth } \\
\text { Temperature }\left({ }^{\circ} \mathrm{C}\right)\end{array}$ & Reference \\
\hline Spray Pyrolysis & 19.4 & 80 & Soda Lime & 400 & 25 \\
\hline Spray Pyrolysis & $3.0 \times 10^{-3}$ & 78 & Soda Lime & 475 & 26 \\
\hline Thermal Evap. & $2.8 \times 10^{-4}$ & 83 & Glass & $300^{*}$ & 27 \\
\hline Sol Gel & $2.8 \times 10^{-2}$ & 82 & Glass & $400 *$ & 28 \\
\hline DC Magn. Sputt. & $3.8 \times 10^{-4}$ & 85 & Glass & RT & 29 \\
\hline RF Magn. Sputt. & $4.0 \times 10^{-4}$ & 82 & PES & RT & 30 \\
\hline Pulsed Laser Dep. & $5.4 \times 10^{-4}$ & 75 & Corning & 400 & 31 \\
\hline RF Magn. Sputt. & $3.1 \times 10^{-3}$ & 80 & PET & RT & This work \\
\hline
\end{tabular}

*Thermal annealing 


\section{References}

1. Cattin L, Bernède JC, Morsli M. Toward indium-free optoelectronic devices: dielectric/metal/dielectric alternative transparent conductive electrode in organic photovoltaic cells. Physica Status Solidi A. 2013;210(6):1047-1061.

2. Fortunato E, Ginley D, Hosono H, Paine DC. Transparent Conducting Oxides for Photovoltaics. MRS Bulletin. 2007;32(3):242-247.

3. Quang LH, Kuan LS, Liang GGK. Structural and electrical properties of single crystal indium doped $\mathrm{ZnO}$ films synthesized by low temperature solution method. Journal of Crystal Growth. 2010;312(3):437-442.

4. Park YR, Nam E, Boo JH, Jung D, Suh SJ, Kim YS. Hydrogenated In-doped ZnO Thin Films for the New Anode Material of Organic Light Emitting Devices: Synthesis and Application Test. Bulletin of the Korean Chemical Society. 2007;28(12):2396-2400.

5. Dikovska AO, Atanasov PA, Tonchev S, Ferreira J, Escoubas L. Periodically structured $\mathrm{ZnO}$ thin films for optical gas sensor application. Sensors and Actuators A: Physical. 2007;140(1):1923.

6. Suvaci E, Özer IO. Processing of textured zinc oxide varistors via templated grain growth. Journal of the European Ceramic Society. 2005;25(9):1663-1673.

7. Rambu AP, Sirbu D, Sandu AV, Prodan G, Nica V. Influence of In doping on electro-optical properties of $\mathrm{ZnO}$ films. Bulletin of Materials Science. 2013;36(2):231-237.

8. Becerril M, Silva-López H, Guillén-Cervantes A, Zelaya-Ángel O. Aluminum-doped $\mathrm{ZnO}$ polycrystalline films prepared by co-sputtering of a $\mathrm{ZnO}-\mathrm{Al}$ target. Revista Mexicana de Física. 2014;60:27-31.

9. Socol G, Socol M, Stefan N, Axente E, Popescu-Pelin G, Craciun $\mathrm{D}$, et al. Pulsed laser deposition of transparent conductive oxide thin films on flexible substrates. Applied Surface Science. 2012;260:42-46

10. Kim DH, Cho NG, Kim HG, Kim ID. Highly Transparent InGaZnO4 Thin Film Transistors Using Indium-Doped $\mathrm{ZnO}$ Electrodes on Plastic Substrate. Electrochemical and Solid-State Letters. 2009;12(6):H198-H201.

11. Huang C, Wang M, Liu Q, Cao Y, Deng Z, Huang Z, et al. Physical properties and growth kinetics of co-sputtered indiumzinc oxide films. Semiconductor Science and Technology. 2009;24(9):095019.

12. Fortunato E, Barquinha P, Pimentel A, Gonçalves A, Marques A, Pereira L, et al. Recent advances in $\mathrm{ZnO}$ transparent thin film transistors. Thin Solid Films. 2005;487(1-2):205-211.

13. Lee C, Park A, Cho Y, Park M, Lee WI, Kim HW. Influence of $\mathrm{ZnO}$ buffer layer thickness on the electrical and optical properties of indium zinc oxide thin films deposited on PET substrates. Ceramics International. 2008;34(4):1093-1096.

14. Hara H, Shiro T, Yatabe T. Optimization and Properties of $\mathrm{Zn}$ Doped Indium Oxide Films on Plastic Substrate. Japanese Journal of Applied Physics. 2004;43(Pt 1 n2):745.

15. Nomura K, Ohta H, Takagi A, Kamiya T, Hirano M, Hosono H. Room-temperature fabrication of transparent flexible thin-film transistors using amorphous oxide semiconductors. Nature. 2004;432(7016):488-492.

16. Quevedo-Lopez MA, Wondmagegn WT, Alshareef HN, Ramirez-Bon R, Gnade BE. Thin film transistors for flexible electronics: contacts, dielectrics and semiconductors. Journal of Nanoscience and Nanotechnology. 2011;11(6):5532-5538.

17. Fortunato EMC, Barquinha PMC, Pimentel ACMBG, Gonçalves AMF, Marques AJS, Pereira LMN, et al. Fully Transparent $\mathrm{ZnO}$ Thin-Film Transistor Produced at Room Temperature. Advanced Materials. 2005;17(5):590-594.

18. Sandoval-Paz MG, Ramírez-Bom R. Indium tin oxide films deposited on polyethylene naphthalate substrates by radio frequency magnetron sputtering. Thin Solid Films. 2009;517(8):2596-2601.

19. Sandoval-Paz MG, Ramírez-Bom R. Optical and structural properties of chemically deposited CdS thin films on polyethylene naphthalate substrates. Thin Solid Films. 2011;520(3):999-1004.

20. 20. XRD reference card 01-089-1397.

21. Khan AA. X-ray determination of thermal expansion of zinc oxide. Acta Crystallographica. 1968;24(3):403.

22. Pankove JI. Optical Processes in semiconductors. $1^{\text {st }}$ ed. New York: Dover Publications; 1975. 412 p.

23. Fahlteich J, Fahland M, Schönberger W, Schiller N. Permeation barrier properties of thin oxide films on flexible polymer substrates. Thin Solid Films. 2009;517(10):3075-3080.

24. Ou ECW, Hu L, Raymond GCR, Soo OK, Pan J, Zheng Z, et al. Surface-Modified Nanotubes Anodes for High Performance Organic Light-Emitting Diode. ACS Nano. 2009;3(8):22582264.

25. Kumar PMR, Kartha CS, Vijayakumar KP, Abe T, Kashiwaba $\mathrm{Y}$, Singh F, et al. On the properties of indium doped $\mathrm{ZnO}$ thin films. Semiconductor Science and Technology. 2005;20(2):120.

26. Lucio-López MA, Luna-Arias MA, Maldonado A, de la L Olvera M, Acosta DR. Preparation of conducting and transparent indium-doped $\mathrm{ZnO}$ thin films by chemical spray. Solar Energy Materials and Solar Cells. 2006;90(6):733-741.

27. Palimar S, Bangera KV, Shivakumar GK. Study of the doping of thermally evaporated zinc oxide thin films with indium and indium oxide. Applied Nanoscience. 2013;3(6):549-553.

28. Luna-Arredondo EJ, Maldonado A, Asomoza R, Acosta DR, Meléndez-Lira M, de la L Olvera M. Indium-doped $\mathrm{ZnO}$ thin films deposited by the sol-gel technique. Thin Solid Films. 2005;490(2):132-136

29. Song YS, Park JK, Kim TW, Chung CW. Influence of process parameters on the characteristics of indium zinc oxide thin films deposited by DC magnetron sputtering. Thin Solid Films. 2004;467(1-2):117-120.

30. Jun DG, Cho HH, Jo DB, Lee KM. Fabrication of IZO thin films for flexible organic light emitting diodes by RF magnetron sputtering. Journal of Ceramic Processing Research. 2012;13(Sp 2):s260-s264.

31. Kim PY, Lee JY, Lee HY, Lee SL, Cho NI. Structure and Properties of IZO Transparent Conducting Thin Films Deposited by PLD Method. Journal of the Korean Physical Society. 2008;53(1):207-211. 